\title{
Hes5.9 Coordinate FGF and Notch Signaling to Modulate Gastrulation via Regulating Cell Fate Specification and Cell Migration in Xenopus tropicalis
}

\author{
Xiao Huang ${ }^{1, * \mathbb{C}}$, Liyue Zhang ${ }^{2}$, Shanshan Yang ${ }^{3}$, Yongpu Zhang ${ }^{3}$, Mingjiang $\mathrm{Wu}^{3}$ \\ and Peichao Chen ${ }^{3, *(1)}$ \\ 1 College of Life Sciences, Zhejiang University, Hangzhou 310058, China \\ 2 The First affiliated Hospital, College of Medicine, Zhejiang University, Hangzhou 310003, China; \\ zhangliyue@zju.edu.cn \\ 3 College of Life and Environmental Science, Wenzhou University, Wenzhou 325035, China; \\ syang0966@gmail.com (S.Y.); zhangyp@wzu.edu.cn (Y.Z.); wumingjiangwz@163.com (M.W.) \\ * Correspondence: xh220@zju.edu.cn (X.H.); chenpeichao@wzu.edu.cn (P.C.); \\ Tel.: +86-571-8820-6786 (X.H.); +86-577-8659-5039 (P.C.); \\ Fax: +86-571-8820-6485 (X.H.); +86-577-8668-9079 (P.C.)
}

Received: 28 September 2020; Accepted: 13 November 2020; Published: 18 November 2020

\begin{abstract}
Gastrulation drives the establishment of three germ layers and embryonic axes during frog embryonic development. Mesodermal cell fate specification and morphogenetic movements are vital factors coordinating gastrulation, which are regulated by numerous signaling pathways, such as the Wnt (Wingless/Integrated), Notch, and FGF (Fibroblast growth factor) pathways. However, the coordination of the Notch and FGF signaling pathways during gastrulation remains unclear. We identified a novel helix-loop-helix DNA binding domain gene (Hes5.9), which was regulated by the FGF and Notch signaling pathways during gastrulation. Furthermore, gain- and loss-of-function of Hes5.9 led to defective cell migration and disturbed the expression patterns of mesodermal and endodermal marker genes, thus interfering with gastrulation. Collectively, these results suggest that Hes5.9 plays a crucial role in cell fate decisions and cell migration during gastrulation, which is modulated by the FGF and Notch signaling pathways.
\end{abstract}

Keywords: Hes5.9; FGF; Notch; gastrulation; cell fate specification; cell migration

\section{Introduction}

Embryogenesis is an extremely complex process. That fertilized eggs are developed to shaped individuals, rather than mounds of pluripotent cells, is largely due to a short period termed gastrulation, which comprises a great many critical events, such as morphogenetic movements, specification of body axes and germ layer, and body plan establishment. By temporal-spatial coordination of cell specification and dynamic cell movement, a three germ layer body plan is established, accompanied by embryonic axis formation, during gastrulation. Primordial organs or tissue rudiments are then formed along the axis and ultimately develop into functional organs or tissues. Thus, gastrulation plays pivotal roles during embryogenesis and organogenesis. During gastrulation, the most dramatic morphogenetic change takes place on mesodermal cells, which are specified and spread between ectoderm and endoderm. To date, research from represented model organisms has revealed that numerous signaling pathways, such as the Wnt (Wingless/Integrated), FGF (Fibroblast growth factor), BMP (Bone morphogenetic protein), Notch, and TGF- $\beta$ (Transforming growth factor-beta)/Nodal signaling pathways [1,2], are involved in mesoderm specification and movement. However, the molecular mechanisms and temporal-spatial orchestrations of these signaling still remain largely obscure. 
Although the manifestations of cell movement during gastrulation differ between phyla, some evolutionarily conserved movements, such as epiboly, internalization, convergence, and extension can be characterized [3]. The amphibian model Xenopus species contributes greatly to understanding the molecular and cellular mechanisms during gastrulation. In Xenopus, gastrulation is typically driven by convergent extension, intercalation, and cell migration. Convergent extension plays a pivotal role in elongating the dorsal marginal zone along the anteroposterior axis [4], which drives the axial and paraxial mesodermal tissues, narrowing (convergence) and lengthening (extension), and also results in blastopore closure and anteroposterior body axis elongation [5,6]. The FGF signaling is reported to modulate multiple developmental processes during early embryogenesis [7-9]. During Xenopus gastrulation, FGF signaling plays an integral role in the induction and maintenance of mesoderm [10], and also regulates morphogenetic movements directly or indirectly [7]. However, it remains equivocal how FGF signaling interplays with other signaling pathways during the induction, maintenance, and specification of different mesodermal regions.

The Notch signaling pathway is conserved in metazoans, which has usually been shown to modulate cell fate decision and form the boundary between embryonic tissues [11]. The Notch receptors bind to their adjacent cells' ligands (Deltas), resulting in cleavage and release of the intracellular domain of Notch (NICD), which then are translocated into the nucleus and interact with CSL (a DNA-binding protein named CBF1 in humans; $\mathrm{Su}(\mathrm{H})$ in Drosophila; LAG1 in C. elegans) to form a trans-activating complex on the promoters of downstream target genes. The hairy-enhancer of split (Hes)/hairy-enhancer of split related with YRPW motif (Hey) family members [12] are not all direct effector genes of the Notch signaling pathway. They encode basic helix-loop-helix (bHLH) transcriptional repressors that control cell fate decisions and cell population expansion. For example, mouse Hes1 and Hes 5 can inhibit neuronal differentiation while promoting the proliferation of neural progenitors in the embryonic brain [13]. In Xenopus, Hes3 [14] and Hes4 (Hairy2) [15] mediate the Notch signaling on neural crest induction on the ridge of the neural plate board. Interestingly, there is clear evidence that Notch signaling is active from the beginning of gastrulation in Xenopus. For example, components of the Notch pathway such as Notch, and Serrate- $1 \mathrm{Su}(\mathrm{H}) 1$ are present maternally and zygotically [16,17], ligands such as Delta- 1 and Delta-2 are present in the marginal zone as a ring encircling the blastopore at early gastrula [18-20], and more importantly, Notch signaling has been reported to be involved in the segregation and boundary formation of the three germ layers in Xenopus during gastrulation [21].

Intriguingly, on integration with other signaling pathways, gastrulation is cellular context responsive, and delicately fine-tuned by Notch signaling [22,23]. The existence has been reported of coordination between FGF and Notch signaling in the establishment of the proper periodicity of vertebrate somite [22,24], ear development [25], and sensory neuron formation [26], via specific target genes. Thus, whether FGF and Notch signaling coordinate during gastrulation, and what are the key targets, are of great interests for elucidating the molecular events and the underlying mechanism of specification and patterning of the germ layers.

We previously screened the differential expression transcripts under the influence of FGF signaling in frog Xenopus tropicalis gastrula by treating with FGFR (Fibroblast growth factor receptor) inhibitor SU5402. A novel basic helix-loop-helix gene (Hes5.9) has been isolated. In this work, we report the expression and mainly characterize the function of Hes5.9 by microinjection of synthetic Hes5.9 mRNA, and antisense oligonucleotides respectively. In general, our results demonstrate that Hes5.9 may function as a transcriptional factor and be regulated by the FGF and Notch signaling, which is critical for cell fate determination and gastrulation during early embryonic development. 


\section{Materials and Methods}

\subsection{Animal Ethics and Embryo Manipulation}

Xenopus tropicalis (Nigerian) were purchased from NASCO (USA), then bred and maintained in our lab. All animal procedures were performed in full accordance with the requirements of the Regulation on the Use of Experimental Animals in Zhejiang Province. This work was specifically approved by the Animal Ethics Committee of the School of Medicine, Zhejiang University (ETHICS CODE Permit NO. 14887, issued by the Animal Ethics Committee in the School of Medicine, Zhejiang University). In brief, ovulation was induced by injection of human chorionic gonadotropin (HCG) into the dorsal lymph sac of mature frogs; male and female frogs were injected with 150 and 200 units of HCG, respectively. The embryos were dejellied by $2 \%$ cysteine ( $\mathrm{pH} 8.0$ ) and then cultured in $0.1 \times$ Marc's modified ringer solution (MMR). Developmental stages were assessed according to Nieuwkoop and Faber (1994). For drug treatment, we incubated the embryos in 0.1× MMR solution containing $20 \mu$ M SU5402 (Santa Cruz) or Dimethyl sulfoxide (DMSO, Sigma) at stage 8, and then removed the solution at stage 11 .

\subsection{Multiple Sequence Alignment and Phylogenetic Tree Construction}

The relative protein sequences were retrieved from NCBI, Xenbase, and Ensemble databases, and then aligned via DNAMAN (Lynnon Biosoft, CA, USA) with default parameters. Phylogenetic trees were constructed by neighbor-joining algorithm, and displayed via DNAMAN. The proximal elements of promoters were obtained as described $[27,28]$, and predicted at http://jaspar.genereg.net.

\subsection{RNA Extraction, Reverse Transcription-PCR, and cDNA Cloning}

Different developmental stage embryos were collected. After homogenizing with RNAiso plus (Takara), chloroform was added. The homogenate was then centrifuged and divided into three layers, the total RNA was precipitated from the upper aqueous layer with isopropanol, and impurities removed with 70\% ethanol. After that, the RNA degradation and contamination were detected by $1 \%$ agarose gel electrophoresis; $1 \mu \mathrm{g}$ of total RNA was reversed to cDNA by using oligonucleotide (dT)-tailed primer and Reverse Transcriptase M-MLV (Takara), $10 \mu \mathrm{L}$ reaction volume including $1 \mu \mathrm{g}$ total RNA, $50 \mu \mathrm{M}$ Oligo(dT)12-18 primer, 5× M-MLV Buffer, 10 mM dNTP Mixture, 40 U/ $\mu L$ RNase Inhibitor, 200 U/ $\mu \mathrm{L}$ RTase M-MLV, and RNase-free water, the mixture was incubated at $42{ }^{\circ} \mathrm{C}$ for $1 \mathrm{~h}$, and then the reaction was stopped by heating at $70^{\circ} \mathrm{C}$ at $15 \mathrm{~min}$. The primers with restriction sites for SmaI and NotI were designed to amplify the full length of Hes5.9, forward: $5^{\prime}$-atacccgggACTACAGACACGTGGACTTA-3' ; reverse: $5^{\prime}$-attgcggccAACAAACAATTTATTACATG-3'. Simultaneously, the constructs of the PCR products and pCS107 vector were digested with EcoRI and XhoI, then purified and ligated with T4 DNA ligase (Thermo) at $22{ }^{\circ} \mathrm{C}$. The ligation products were transformed into TG1 competent cells and herein the cells were spread on LB plates containing ampicillin ( $50 \mu \mathrm{g} / \mathrm{mL})$. The Hes5.9 fragment inserted into a vector was verified by colony PCR, the pCS107-Hes5.9 plasmid was extracted from $2 \mathrm{~mL}$ overnight culture by SanPrep Kit (Sangon), and then using SP6 as a primer to sequence, the Hes5.9 from pCS107-Hes5.9 plasmid and the sequences were aligned with NCBI.

\section{4. $m$ RNA Synthesis and Microinjection}

The plasmid pCS107-Hes5.9 was linearized with ApaI (Takara), then capped mRNAs were synthesized using the mMESSAGE mMACHINE SP6 Kit (Ambion), and purified by MEGAclear Kit (Ambion). In brief, the following transcription reaction was carried out at room temperature: with $2 \times$ NTP/CAP, 10× Reaction buffer, SP6 enzyme Mix, $1 \mu \mathrm{g}$ linear template, and Nuclease-free water, the compound was incubated at $37^{\circ} \mathrm{C}$ for $1 \mathrm{~h}$, in sequent, the RNA was absorbed on the membrane in the filter cartridge, and then contaminants were washed away, lastly, mRNA was resuspended in a low salt buffer. The mRNA was bilaterally injected into the dorsal of the four-cell stage blastomere, meanwhile, the fluorescent dextran was co-injected as a lineage tracer. 


\subsection{Quantitative Reverse Transcription PCR (RT-qPCR)}

Total RNA was extracted from X. tropicalis embryos according to the above-mentioned method, after synthesizing cDNA. RT-qPCR reactions were performed in triplicate for each sample, using a FastStart Universal SYBR Green Master (Roche) in CFX-Connect Real-Time System (BIO-RAD). The relative expression level of each target was normalized to the expression level of ornithine decarboxylase $(O d c)$.

\subsection{Whole-Mount in situ Hybridization}

For the hybridization studies, the digoxigenin labeled antisense RNA probe of Hes5.9 was prepared by linearizing the pCS107-Hes5.9 plasmid with SmaI (Takara), and transcribing with T7 RNA polymerase (Promega). The different stages of embryos were collected and fixed in MEMFA (0.1 M MOPS, $2 \mathrm{mM}$ EGTA, $1 \mathrm{mM} \mathrm{MgSO}_{4}, 3.7 \%$ formaldehyde) for $2 \mathrm{~h}$ at room temperature, then these embryos were permeabilized by incubating them for about $15 \mathrm{~min}$ at room temperature in proteinase $\mathrm{K}$ (Roche; final concentration, $2.8 \mu \mathrm{g} / \mathrm{mL}$ ), when the process of acetylation, fixation, and pre-hybridization was finished, the embryos were incubated in fresh hybridization buffer containing $0.5 \mathrm{ug} / \mathrm{mL}$ probe, and hybridized overnight at $60^{\circ} \mathrm{C}$. The embryos were washed with $2 \times$ saline sodium citrate (SSC), and $0.2 \times \mathrm{SSC}$ at $60^{\circ} \mathrm{C}$, to remove the excess probe, then the embryos were washed twice with maleic acid buffer (MAB), MAB was replaced with blocking reagent (MAB, 2\% Boehringer Mannheim blocking reagent, and $10 \%$ inactivated sheep serum), incubated for $2 \mathrm{~h}$ at room temperature; embryos were then incubated with antibody solution (Roche; anti-digoxigenin alkaline phosphatase (AP) antibody, 1:2000) overnight at $4{ }^{\circ} \mathrm{C}$. The free antibody was removed by washing $3 \times 30 \mathrm{~min}$ in $\mathrm{MAB}$, before chromogenic reaction. We first washed the embryos $2 \times 5 \mathrm{~min}$ at room temperature in alkaline phosphatase (AP) buffer, then incubated the embryos with BM purple (Roche), and when staining becomes apparent, embryos were fixed with MEMFA for $2 \mathrm{~h}$ at room temperature, then bleached with $30 \%$ hydrogen peroxide solution. Finally, the embryos were stored in $1 \times$ phosphate-buffered saline (PBS) for photographing.

\subsection{Animal Cap and Dorsal Marginal Zone (DMZ) Elongation Assays}

The embryos were injected with mRNA into the dorsal blastomeres, or MOs into ventral blastomeres at the four-cell stage embryos. Animal cap explants were excised at stage 8-9, and were cultured in $1 \times$ MBS with antibiotic, or together with $25 \mathrm{pg} / \mathrm{mL}$ recombinant human activin A (R\&D) protein, until stage 17. DMZ explants were excised at stage 10.25 then cultured in $1 \times$ MBS with the antibiotic until stage 17.

\subsection{RNA-Sequencing and Data Analyses}

RNA sequencing was performed on the Illumina HiSeq2000 platform, and paired-end reads were mapped to the reference Xenopus tropicalis transcriptome annotation. HTSeq v0.6.1 was used to count the reads number mapped to each gene. Differential expression analysis of WT and Hes5.9 overexpression was performed by using the DEGSeq R package (1.20.0). The P values were adjusted using the Benjamini and Hochberg method. Corrected $P$-value of 0.005 and $\log 2$ (fold change) of 1 were set as the threshold for significantly differential expression. Gene ontology (GO) enrichment analysis of differentially expressed genes was implemented by the GOseq R package. GO terms with corrected P-value less than 0.05 were considered significantly enriched by differentially expressed genes. KOBAS software was used to test the statistical enrichment of the differential expression genes in KEGG pathways (http://www.genome.jp/kegg/). The DEGs, GO, and KEGG were collected in Supplemental Excel files. 


\section{Results}

\subsection{Hes5.9 is Regulated by the Notch Signaling}

In a systematic screen for differentially expressed transcripts under the influence of FGF signaling in Xenopus tropicalis embryos, we isolated a novel transcript during gastrulation. This transcript was denoted as LOC733709, and now suggested as Hes5.9. However, the biological function of this gene has not been characterized. According to the Ensembl database, LOC733709 is located at the Scaffold GL172709.1, and is comprised of three exons and two introns, which encode a 155-amino acid protein (Supplementary Figure S1).

The Hes proteins consist of three conserved domains: the bHLH domain, the orange domain, and the C-terminal WRPW motif [29]. Hes5.9 shows high identity to the Hes family members by multiple-sequence alignment (Figure 1A). The phylogenetic analysis further revealed that Hes5.9 was closely related to Hes5.7 (Hes9.1) and Hes5 subfamily members (Figure 1B), which are the downstream genes of Notch signaling. Meanwhile, according to the gene locus, Hes5.9 localizes in the Hes5.3 cluster, consisting of Hes5.3-Hes5.10, therefore, Hes5.9 was suggested to be possibly synchronously regulated by the Notch signaling. This was confirmed by transcriptional regulation sequence alignment (Figure 2A) and conserved Notch binding motif prediction (Figure 2B). Hes5.9 contains paired Su(H) sites resembling an SPS, which are flanked by an inverse CCAAT motif, and proximal to the TATA box (Figure 2A). Meanwhile, a high scored Notch binding sequence located at -1966bp was further predicted by JASPAR (Figure 2B). When the embryos were treated with DAPT, an inhibitor of the Notch signaling, from stage 8, the mRNA expression level of Hes5.9 was dramatically downregulated at stage 12 (later gastrula stage), resembling the Notch downstream gene Hes4 (Hairy2) (Figure 2C). Conversely, embryos were microinjected with NICD-GR mRNA at the 4-cell stage, and the mRNA expression level of Hes5.9 and Hes4 were significantly upregulated at stage 12 with dexamethasone induction (Figure 2D). Collectively, Hes5.9 is regulated by the Notch signaling, which might be a target gene of the Notch pathway.

\subsection{Spatiotemporal Expression Pattern of Hes5.9 in Embryonic Development}

During X. tropicalis embryogenesis, the spatiotemporal expression pattern of Hes5.9 was analyzed by WISH and RT-qPCR (Figure 3). It revealed that Hes5.9 was gradually increased from egg to stage 10 (early gastrula stage), and climbed to a plateau during the neurula stages, while after stage 21 (late neurula stage), Hes5.9 gradually declined (Figure 3K). Therefore, Hes5.9 was suggested as a maternally expressed gene, which was confirmed by WISH in the 8-cell stage (Figure 3A). Meanwhile, Hes5.9 was significantly upregulated from the gastrula stages to the neurula stages (Figure $3 \mathrm{~K}$ ) that indicated Hes5.9 might be involved in gastrulation and tissue rudiment determination. The Hes5.9 transcript was observed in the animal pole blastomeres at the early cleavage stage (Figure 3A), and lasted to the blastula stage (Figure $3 \mathrm{~K}$ ). However, no signal was detected in the vegetal pole (Figure 3B). At early gastrula stages, Hes5.9 was expressed throughout the mesoderm except for the dorsal midline mesoderm (Figure 3C and Supplementary Figure S2). Then the signal narrowed toward the paraxial dorsal marginal zone (DMZ) at the early neurula stages and was expressed in the neural plate (Figure 3D). From the late neurula stage to the tailbud stage, the Hes5.9 transcript was presented in the optic vesicle, otic vesicle, forebrain, midbrain, hindbrain, tailbud, and spinal cord (Figure 3E-J). Collectively, it showed that Hes5.9 was mainly expressed in the mesoderm, neural primordium, and tailbud. Therefore, Hes5.9 may play important roles in gastrulation, neural system development, and somitogenesis. 


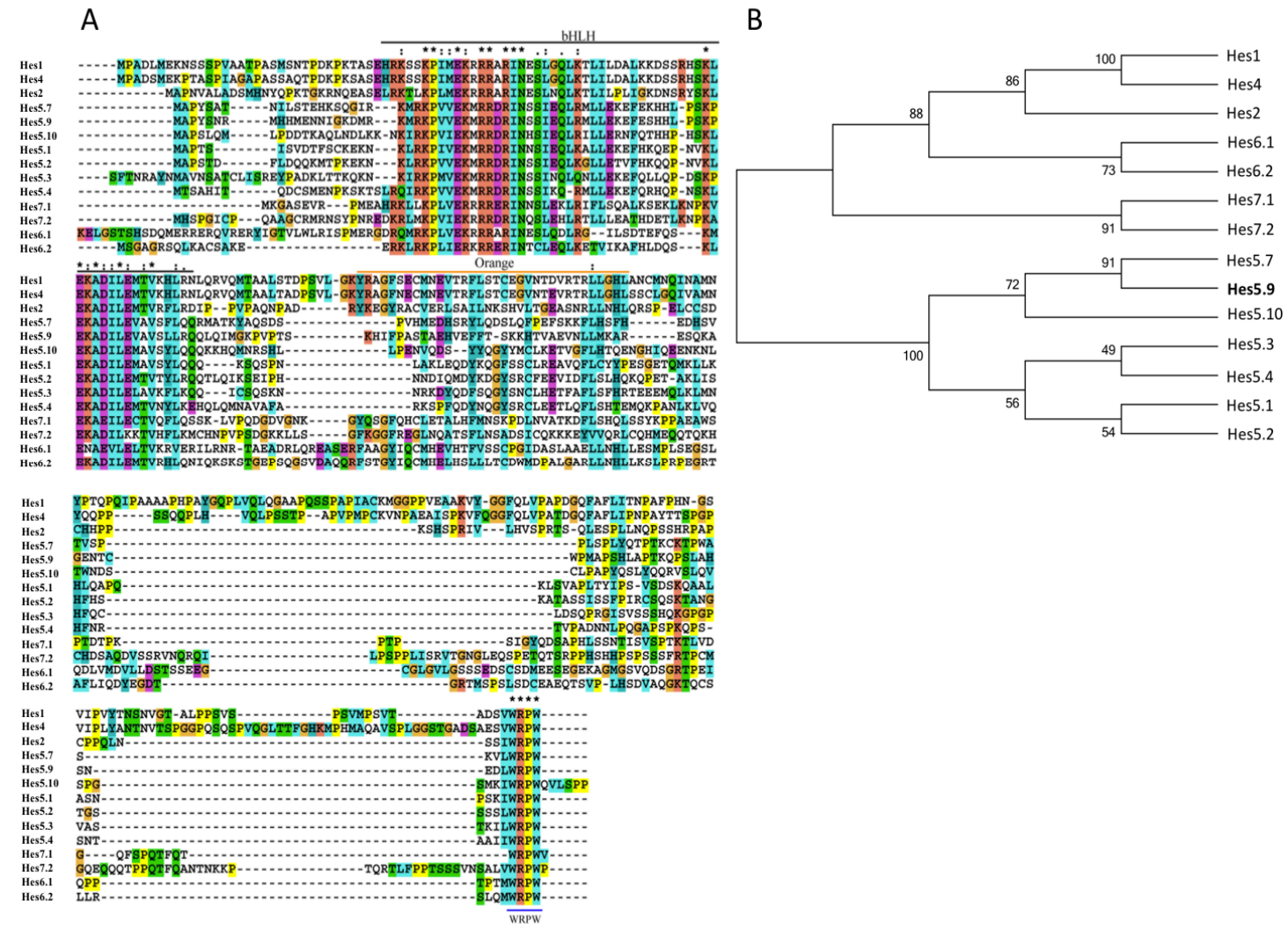

Figure 1. Hes5.9 belongs to the Hes family. (A) Multiple sequence alignment of Xenopus tropicalis Hes5.9 and related proteins. Comparison of the Hes5.9 protein sequence with the related proteins that belong to the Hes family in X. tropicalis. There are three conserved domains: the bHLH domain, the orange domain, and the WRPW sequence at the carboxyl terminus between these proteins. The colors represent different similarity: violet is $100 \%$, pink is $75 \%$ or more, and the blue is $50 \%$ or more. (B) Phylogenetic tree for X. tropicalis Hes5.9 protein. The phylogenetic tree was constructed by using the comparison of full-length protein sequences.

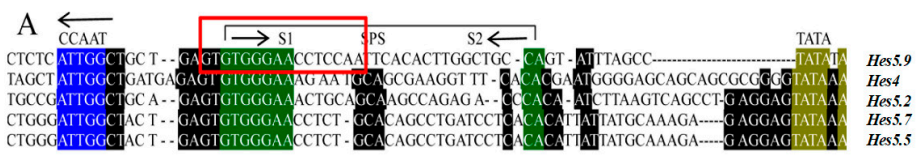

B

\begin{tabular}{|l|l|l|l|l|l|l|l|l|}
\hline \hline 3 putative sites were predicted with these settings (80\%) in sequence named xenTro7_refGene_NM_001044486 \\
\hline Model ID & Model name & Score & Relative score & Start & End & Strand & predicted site sequence \\
\hline MA0085.1 & Su(H) & 10.680 & 0.829467602448566 & 164 & 179 & 1 & tagtgggaaacagtaa \\
\hline MA0085.1 & Su(H) & 12.103 & 0.86348132851648 & 1854 & 1869 & -1 & gtgtgggaaagcacca \\
\hline MA0085.1 & Su(H) & 14.224 & 0.914179229423048 & 1966 & 1981 & 1 & gtgtgggaacctccaa \\
\hline
\end{tabular}

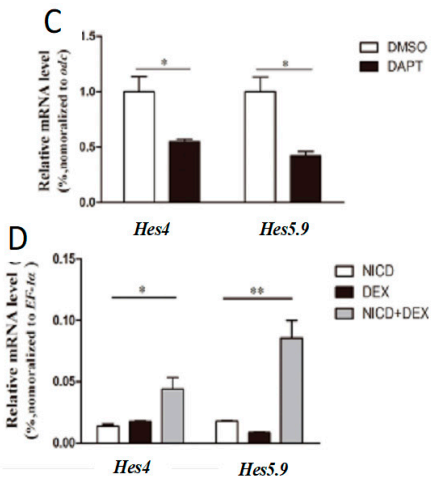

Figure 2. The Hes5.9 is regulated by the Notch signaling. (A) Promoters of Hes5.9, Hes4, Hes5.2, Hes5.7, and Hes5.5 show high and moderate homology of S1 and S2, respectively, in the SPS (green). All exhibit a conserved CCAAT motif (blue) and TATA box (yellow). (B) The predicted Notch binding sequences of Hes5.9. The expression patterns of Hes4 and Hes5.9 are affected by inhibition (C) or induction (D) of the Notch signaling, ${ }^{*} p<0.05 ;{ }^{* *} p<0.01$. 

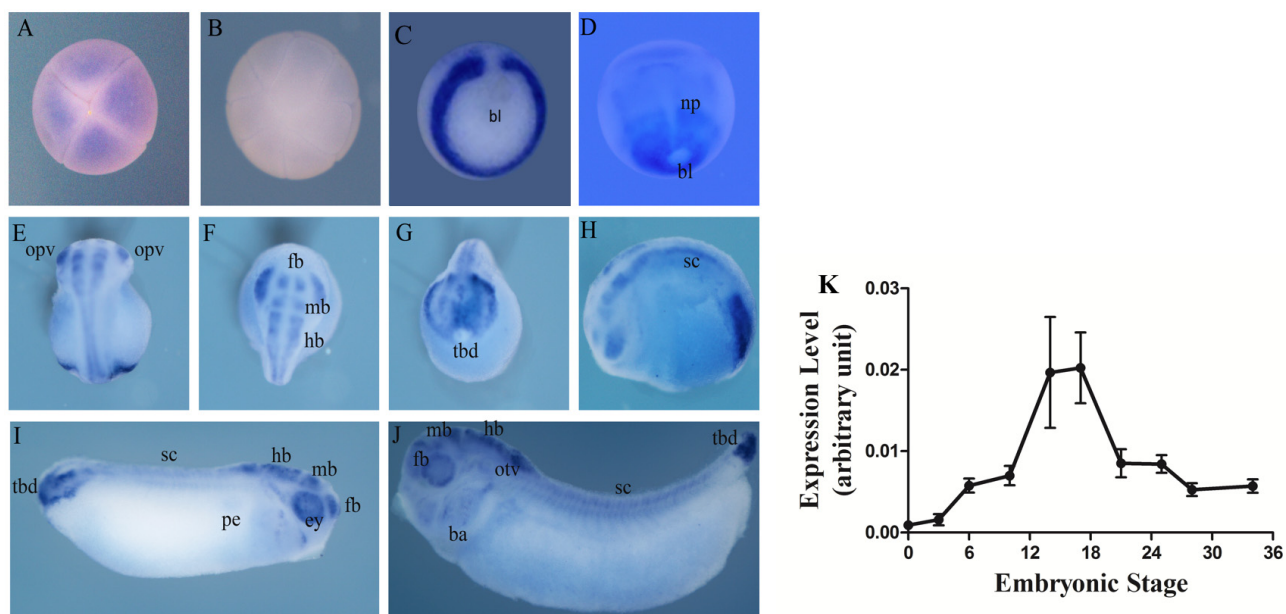

Figure 3. Spatiotemporal expression pattern of Hes5.9 during embryonic development of Xenopus tropicalis. The spatial expression pattern of Hes5.9 mRNA during development, which was examined by whole-mount in situ hybridization (WISH). (A) Cleavage stage 3, animal view; (B) Blastula stage 7, ventral view; (C) Early gastrula stage 10.5, vegetal view, dorsal to the top; (D) Early neurula stage 13, dorsal view, anterior to the top; (E-G) Mid neurula stage 19, dorsal view, anterior to the top in (E); anterior view, dorsal to the bottom in $(\mathbf{F})$; posterior view, dorsal to the top in $(\mathbf{G}) ;(\mathbf{H})$ Late neurula stage 21, lateral view, dorsal to the top; (I) Early tailbud stage 28, lateral view, anterior to the right; (J) Late tailbud stage 35, lateral view, anterior to the left. (K) The temporal expression pattern of mRNA for Hes5.9 during X. tropicalis embryonic development examined by RT-qPCR, and ornithine decarboxylase $(\mathrm{Odc})$ was applied as a constant expression control. Abbreviations, bl: blastopore lip, np: neural plate, sc: spinal cord, ey: eye, tbd: tailbud, fb: forebrain, mb: midbrain, hb: hindbrain, opv: optic vesicle, otv: otic vesicle.

\subsection{The FGF Signaling is Required for the Spatiotemporal Expression Pattern of Hes5.9 during Gastrulation}

The Hes5.9 was originally isolated from a systematic search for differentially expressed transcripts by inhibition of the FGF signaling during gastrulation in X. tropicalis embryos. Interestingly, the WISH results revealed that Hes5.9 shared a similar expression pattern to Myod, a crucial downstream gene of the FGF signaling at the early gastrula stage [30,31]. Therefore, we speculated that Hes5.9 was also regulated by the FGF signaling pathway. As shown in Figure 4, the Hes5.9 was expressed throughout the mesoderm during gastrulation in the DMSO treated embryos (Figure 4A), but dramatically inhibited and dispersed around the blastopore by SU5402 treatment (Figure 4B). This was further validated by RT-qPCR (Figure 4C). In contrast, when upregulation of the FGF signaling by microinjecting embryos with Fgf8b mRNA at the 4-cell stage, the expression level of Hes5.9 was moderately increased at stage 11 (Figure 4D). On other hand, we first inhibited FGF signaling by SU5402 and then recovered FGF signaling by withdrawing SU5402. As shown in Figure 5, after the withdrawal of SU5402, the transcription of Hes5.9 was recovered at the neurula and the tailbud stages. However, the expression level was still much less than that in the mock embryos. Meanwhile, the spatial expression pattern of Hes5.9 was severely interrupted at the neurula and the tailbud stages, which was divergently expressed in the primordium of the neural system, and vaguely among the somite and dorsum (Figure 5). Collectively, the mRNA expression levels of Hes5.9 were downregulated by inhibition of the FGF signaling, and upregulated by overexpression of FGF8b or withdrawing the inhibition of the FGF signaling, which indicated that Hes5.9 was also regulated by the FGF signaling pathway. 

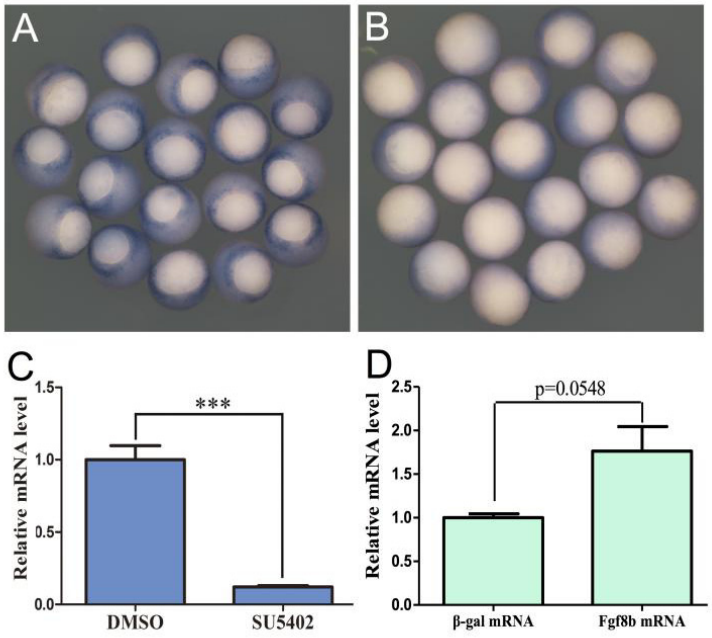

Figure 4. The mRNA expression level of Hes5.9 is regulated by the FGF (Fibroblast growth factor) signaling. The FGFR (Fibroblast growth factor receptor) inhibitor SU5402 was utilized in embryos from stage 9 (pre-gastrula stage) to stage 11 (middle gastrula stage), while the control counterparts were treated with DMSO (Dimethyl Sulfoxide). The results of whole-mount in situ hybridization displayed: compared with DMSO-treated (A), the Hes5.9 mRNA expression level was significantly declined by treatment with $20 \mu \mathrm{M}$ SU5402 (B). A quantitative analysis of Hes5.9 mRNA level was determined at stage 11 by RT-qPCR when the FGF signaling pathway was suppressed by SU5402 (C). (D) RT-qPCR analysis, the mRNA expression level of Hes5.9 in stage 17 when each embryo was injected with $240 \mathrm{pg}$ $F g f 8 b$ mRNA at the four-cell stage, and the Hes5.9 expression was moderately increased. The values were normalized to $O d c,{ }^{* * *} p<0.001$.

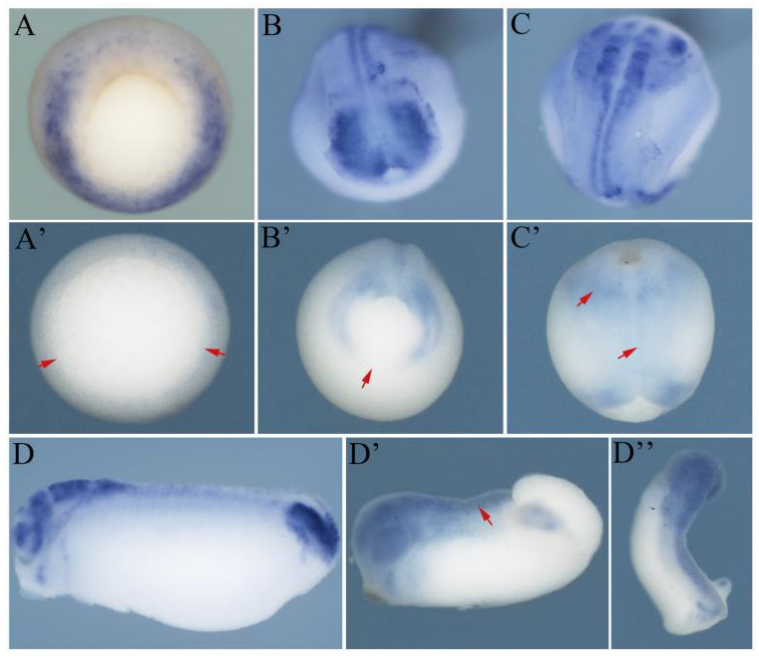

Figure 5. The spatiotemporal expression of Hes5.9 was partially recovered after withdrawing SU5402. The mRNA expression pattern of Hes5.9 was detected by WISH during the middle gastrula in mock embryos (A), and the embryos treated with SU5402 (A'), blastopore view with dorsal up; the late neurula mock embryos (B) and the embryos with withdrawn SU5402 (B'), posterior view with dorsal up; the late neurula mock embryos (C) and the embryos with withdrawn SU5402 (C'), dorsal view with head up; the tailbud stage, mock embryos (D) and embryos with withdrawn SU5402, lateral view (D'); and the embryos with withdrawn SU5402 with dorsal view ( $\left.\mathbf{D}^{\prime \prime}\right)$. The red arrows indicate abnormal expression patterns of Hes5.9.

\subsection{Knockdown of Hes5.9 Results in Defects on Gastrulation}

To explore the functions of Hes5.9 during early embryonic development in X. tropicalis, the embryos were dorsally microinjected at the 4-cell stage with $10 \mathrm{ng} / \mathrm{embryo}$ Hes 5.9 morpholino oligonucleotide 
(MO). However, they did not show obvious differences with the embryos injected with control MO. It was aforementioned that Hes5.9 was highly expressed throughout the mesoderm, including the whole ventral mesoderm at the gastrula stage (Figure 3C), so we changed to knocked down ventral Hes5.9. It showed that three kinds of MOs performed efficiently (Figure 6), and the microinjection was successfully performed (Supplementary Figure S3), for the fluorescent tracers mostly localized among dorsal zone after the neurula and the tailbud stages (Figure 6). Intriguingly, the depletion of Hes5.9 resembled the blocking of FGF signaling by SU5402. Although the blastopore lip formed normally, 81\% (74/91) of embryos were delayed in blastopore closure by knocking down Hes5.9 with MOs at late gastrula (Figure 6, st12). When neurulation initiated, 59\% (54/91) of the Hes5.9 knockdown embryos exhibited failures in blastopore and neural tube closure (Figure 6, st17). Meanwhile, the MOs at anti-splicing sites performed with better efficiency than at the anti-ATG translation start site. Although $92 \%$ of the embryos reached the tailbud stage, $89 \%$ (42/47) of the embryos were shortened in trunk and tail when injected with anti-splicing sites MOs (Figure 6). Therefore, depletion of ventral Hes5.9 led to severe gastrulation defects, and further disturbing the development of the neural system, trunk, and tail.

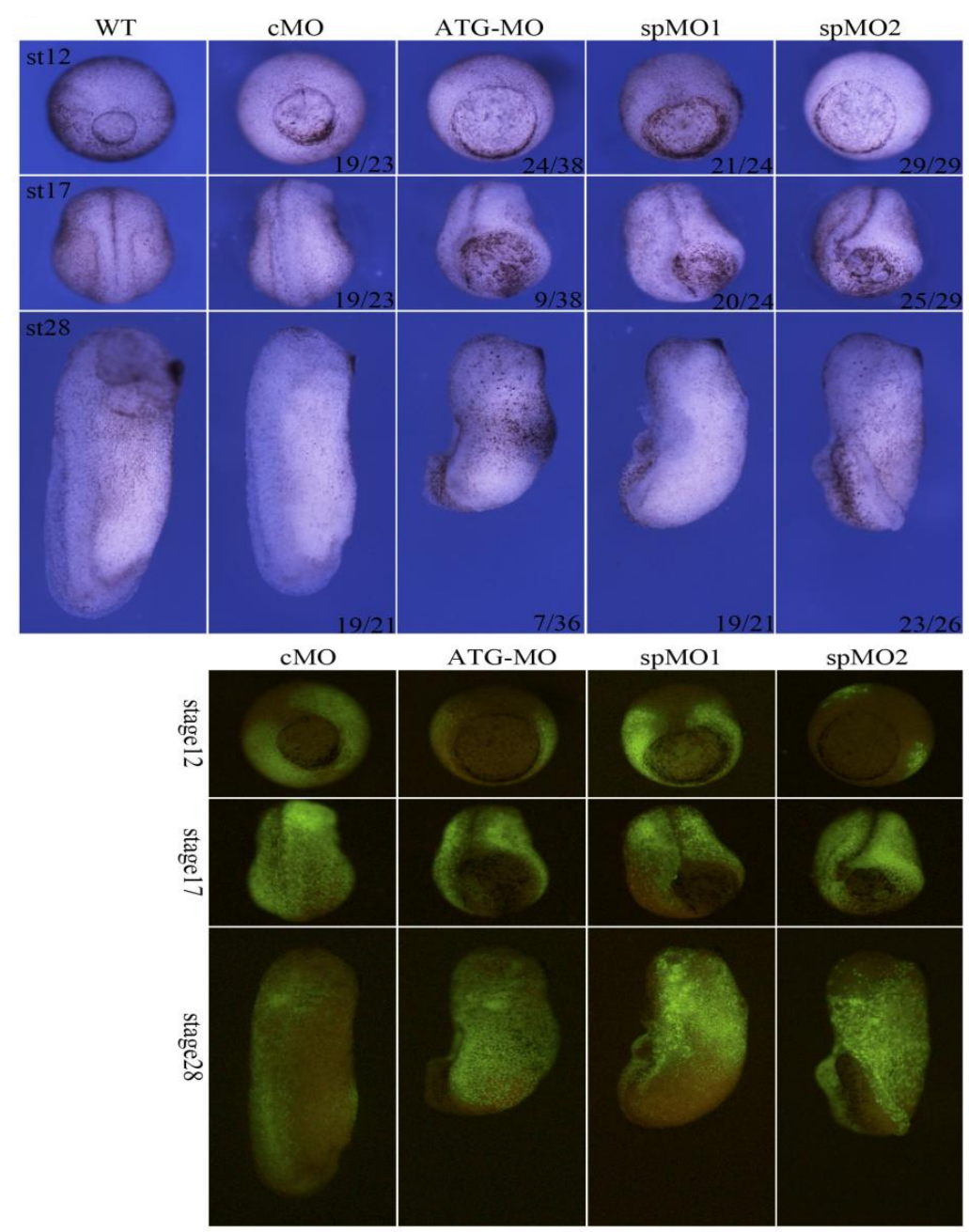

Figure 6. Knockdown of Hes5.9 resulted in defective embryo morphogenesis. $10 \mathrm{ng} \mathrm{MO} / \mathrm{embryo}$ was ventrally injected at the 4-cell stage. Meanwhile, fluorescent dextran was co-injected as a lineage tracer. cMO means control MO, ATG-MO targeting translational start site, while spMO1 and spMO2 binding to splicing sites (more details about scheme and efficiency are shown in supplementary data Figure S3). 


\subsection{Overexpression of Hes5.9 Causes Defects on Gastrulation}

The depletion of Hes5.9 caused severe gastrulation defects (Figure 6), so what about the overexpression of Hes5.9. It showed that the blastopore lip formed normally, but $86.4 \%$ of embryos with Hes5.9 ectopic expression exhibited gastrulation delaying and failed in blastopore and neural tube closure (Figure 7B,D,G). Most of the embryos survived to early tailbud stage (stage25) but exhibited a curved trunk or short tail (Figure 7F). This revealed that overexpression of dorsal Hes5.9 perturbed gastrulation and neurulation, and mainly exhibited open blastopore and abnormal neural fold. As mesoderm cells play pivotal roles in morphogenetic movements, we then examined the expression patterns of the germ layer marker genes that were influenced by Hes5.9 during gastrulation. As shown in Figure 7H, with overexpression of Hes5.9, pan-mesodermal marker Xbra and ventral mesodermal markers Wnt8a, Xnr3, VegT, and Wnt11b were remarkably upregulated, while Chordin and Ventix2.1 were not significantly influenced (Figure 7H). Collectively, this indicated that Hes5.9 might regulate cell fate decisions, thus modulating gastrulation and neurulation.
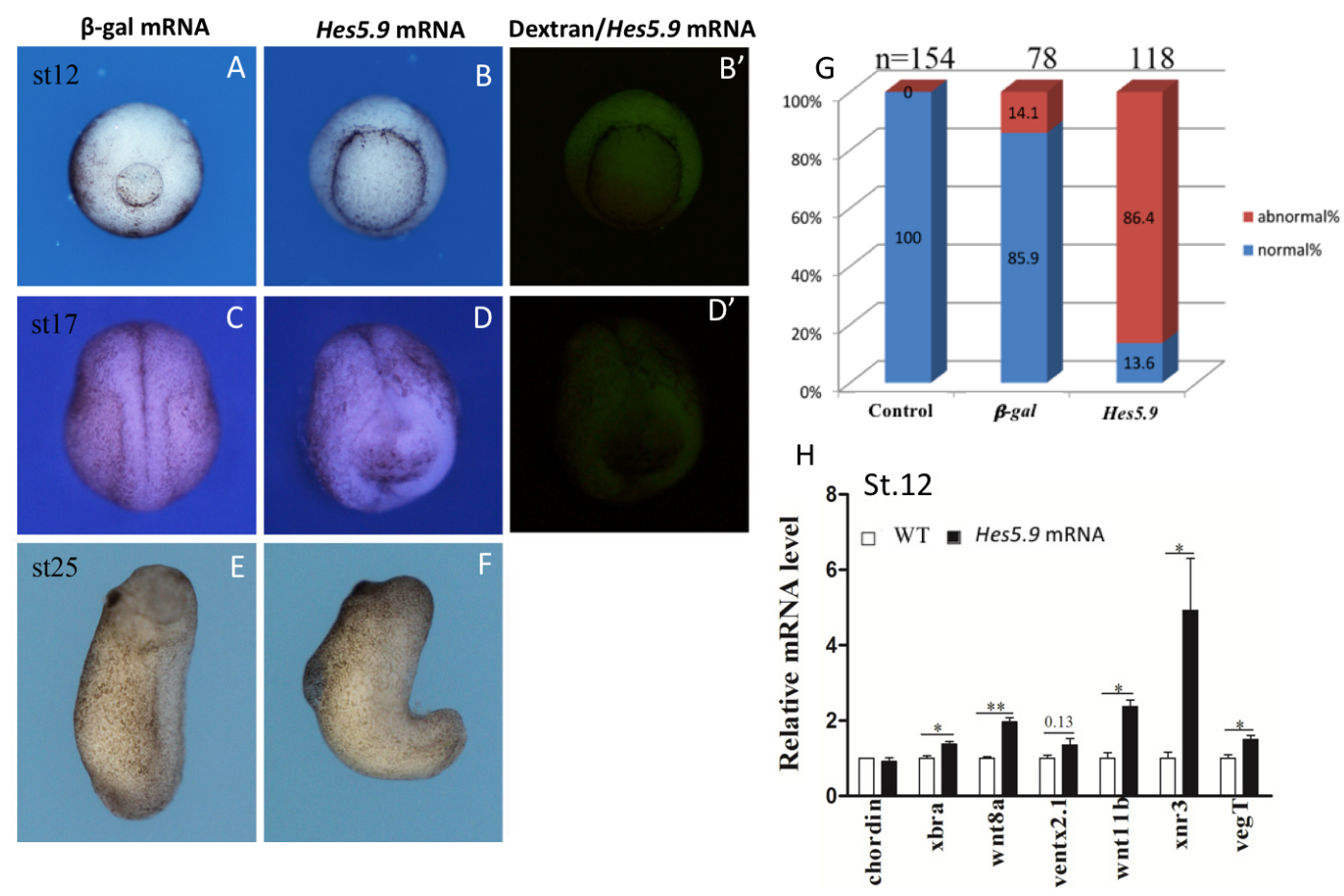

Figure 7. Overexpression of Hes5.9 resulted in defective embryo morphogenesis. Embryos were bilaterally injected dorsally with $250 \mathrm{pg}$ Hes5.9 mRNA at the 4-cell stage, $\beta$-galmRNA injected as a negative control, and dextran co-injected to indicate the inject site. (A-F) Ectopic expression of Hes5.9 mRNA perturbed embryos normal development during gastrulation and neurulation, open blastopore and abnormal neural fold was observed. (G) Statistical analysis of abnormality. (H) The expression levels of the representative marker genes were determined by RT-qPCR at stage $12,{ }^{*} p<0.05 ;{ }^{* *} p<0.01$.

\subsection{Hes5.9 Modulates the Elongation of Animal Cap and DMZ Explants}

Blastopore and neural tube closure are complex processes, while convergent extension and mesoderm migration are the fundamental morphogenetic movements that modulate these processes [32-34]. To address whether Hes5.9 influences convergent extension and/or mesoderm migration, we performed the animal cap elongation assay from the embryos microinjected with Hes5.9 or $\beta$-gal mRNA. The animal caps were dissected at stage 8 and then cultured to equivalent stage 17 . Our data showed that the elongation of animal cap explants was dependent on the activin induction (Figure 8A,B). Meanwhile, the elongation rate is negatively related to the ectopic expression level of Hes5.9 (Figure 8B). We also assessed the expression patterns of some representative marker genes in the animal caps. It showed 
that the expression of chordin and Sox $17 a$ were dramatically downregulated by overexpression of Hes5.9 (Figure 8C). Furthermore, the elongation of DMZ explants was retarded dramatically by either knockdown or overexpression of Hes5.9 (Figure 8D). Collectively, this revealed that Hes5.9 modulated cell fate decision and mesoderm movement by regulating gene transcription and convergent extension.

A

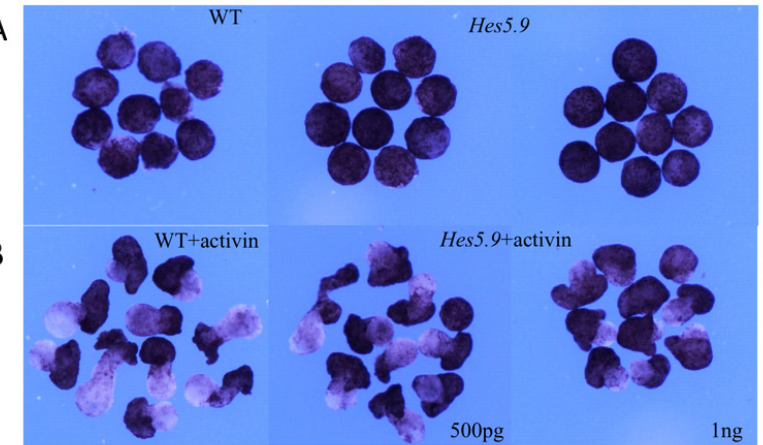

$\mathrm{D}$

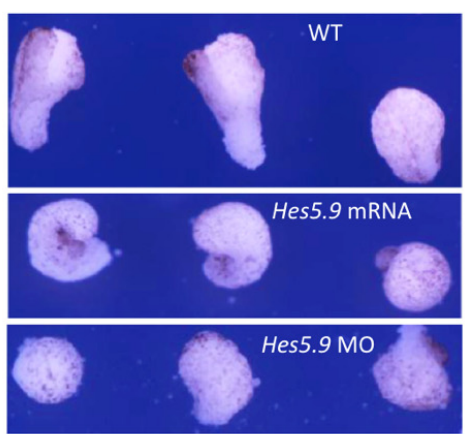

C

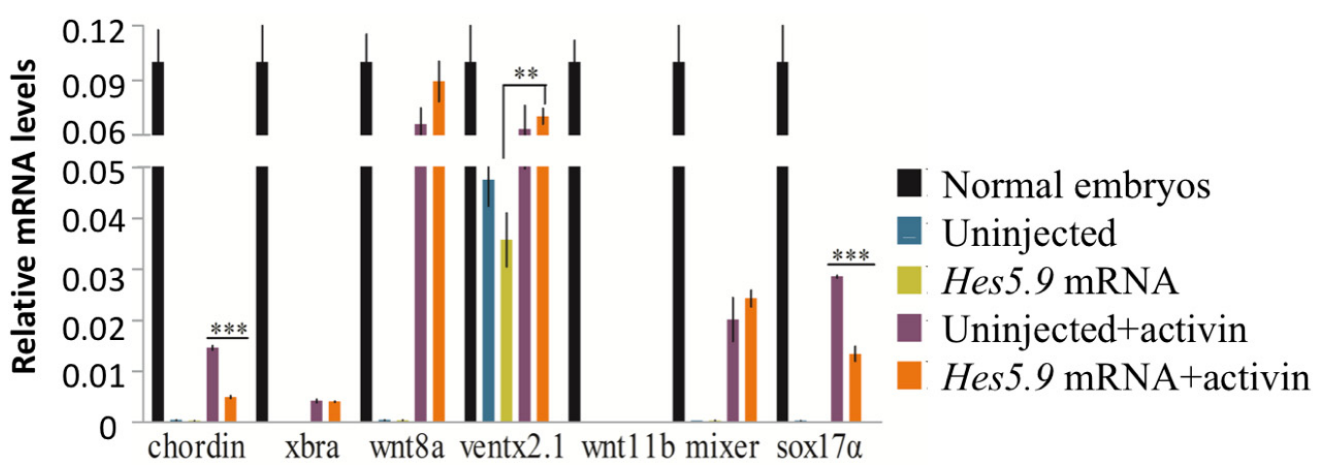

Figure 8. The Hes5.9 inhibited cell fate specification and cell migration. A range of 500 pg-1 ng Hes5.9 mRNA was injected into the destined dorsal cells at the 4-cell stage. Animal caps were dissected from wild type or Hes5.9 overexpressed embryos at stage 8 and then cultured in $0.1 \times$ MMR without (A) or with (B) activin $(25 \mathrm{pg} / \mathrm{mL})$, and these explants were captured until the equivalent of stage 17. (C) The expression patterns of the marker genes were determined by RT-qPCR. (D) The dorsal marginal zone (DMZ) explants were dissected at stage 10.25 and a picture taken at stage $17,{ }^{* *} p<0.01 ; * * * 00.001$.

\subsection{Transcriptomics Analysis of Hes5.9 Ectopic Expression in Late Gastrula Stage}

The embryos microinjected with Hes5.9 or $\beta$-gal mRNA (as control) were harvested at stage 11.5. Thereafter, they were assessed by RNA-Seq and bioinformatics analysis. It showed that 12,362 transcripts were overlapped in the Hes5.9-overexpressed and control groups, while 966 and 436 transcripts were uniquely expressed in the Hes5.9-overexpressed and control groups, respectively (Figure 9A). Meanwhile, there were 4799 genes differentially expressed; whereas 2448 genes were upregulated, 2351 genes were downregulated with overexpression of Hes5.9 (Figure 9B). The results further indicated that dorsal-ventral axis formation, cell cycle, apoptosis, p53 signaling pathway, and FoxO signaling pathways were influenced by ectopic expression of Hes5.9 (Figure 9C and Supplementary Tables S1 and S2). Adherence junction, focal adhesion, and regulation of actin cytoskeleton were downregulated by ectopic expression of Hes5.9, which is consistent with the deficiency of animal cap and DMZ elongations (Figure 9C and Supplementary Tables S1 and S2). Intriguingly, we also found that the insulin signaling pathway and a battery of metabolism-associated genes were enriched by the ectopic expression of Hes5.9 (Figure 9C and Figure S3). However, Hes5.9 function in metabolism and development requires further elucidation. 

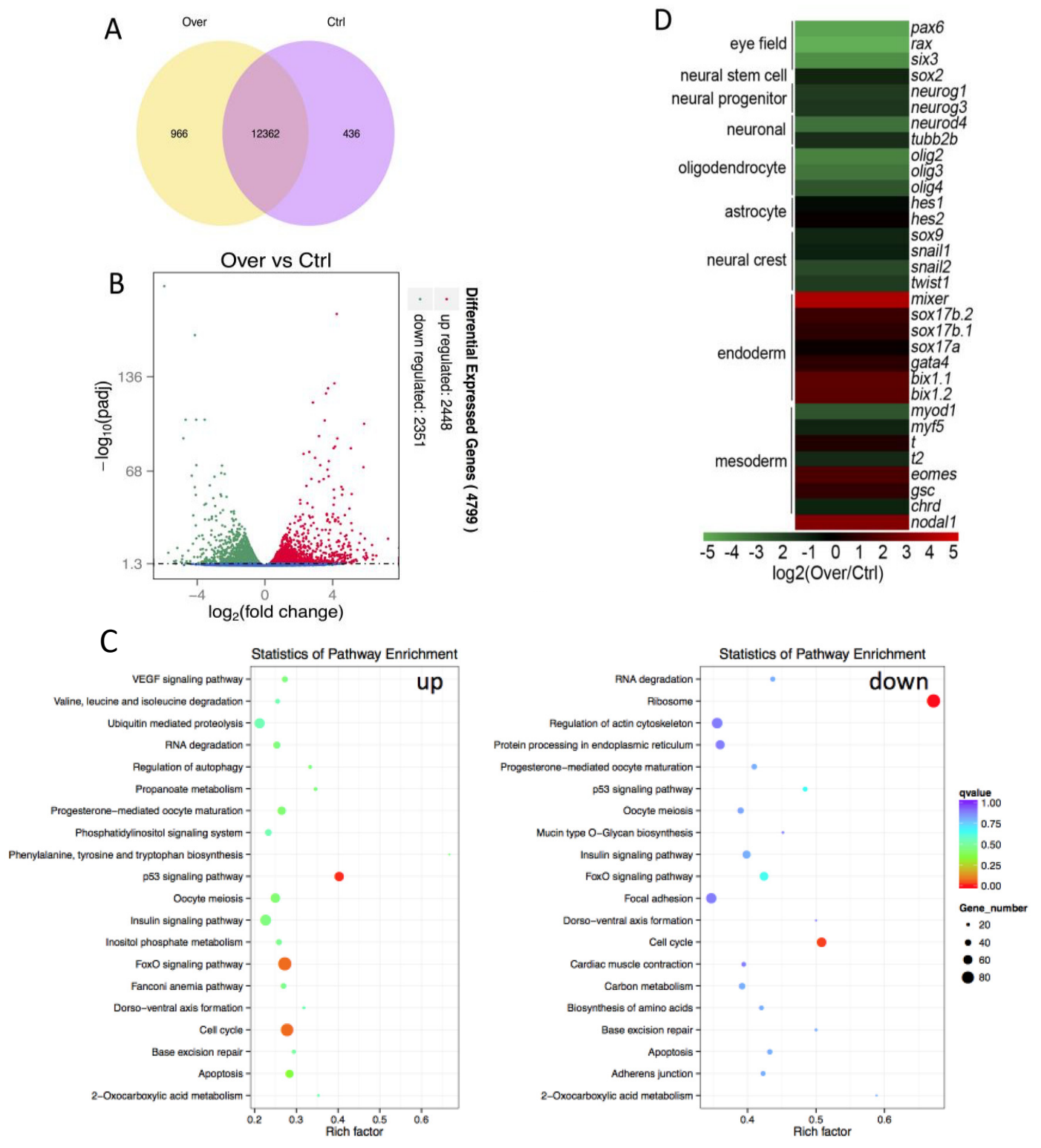

Figure 9. Transcriptomic analysis of Hes5.9 overexpression at stage 12. (A) Total genes nominated in a Venn diagram. (B) Differential expressed genes by volcano diagram. (C) Differentially expressed genes were annotated in KEGG pathways. (D) Neurogenesis associated genes were displayed.

Overexpression of Hes5.9 significantly decreased the expression of neural progenitor markers Neurog1 and Neurog3, neuronal markers Neurod4 and Tubb2b, and eye field markers Pax6, Rx, and Six3, which indicates that Hes5.9 could inhibit neural tissue formation. Meanwhile, overexpression of Hes5.9 diminished the oligodendrocyte markers Olig2, Olig3, and Olig4, but not the astrocyte markers Hes1 and Hes2, thus indicating that Hes5.9 functions as a both neuronal and oligodendrocyte inhibitor. We also noticed that overexpression of Hes5.9 diminished neural crest marker Snail2 and Twist1. Besides, we found that overexpression of Hes5.9 significantly upregulated endoderm markers such as Mixer, Sox17b, Sox17a, Gata4, and Bix1. We further checked mesoderm markers and found that the pan-mesoderm marker T (Bra), Eomes, and the dorsal mesoderm marker Gsc were also upregulated, while muscle mesoderm markers Myod and Myf5 were downregulated by overexpression of Hes5.9. To explain this situation, we investigated the expression level of the meso-endoderm inducer Nodal. We found that Nodal1 was significantly upregulated when Hes5.9 was overexpressed in Xenopus embryos. 


\section{Discussion and Conclusions}

In this study, we characterized the roles of Hes5.9 in regulating cell fate decisions and cell migration in gastrulating Xenopus tropicalis embryos, which were regulated by the FGF and Notch signaling pathways during gastrulation. Results indicated the coordination of the FGF and Notch signaling pathways through fine-tuning of the expression pattern of Hes5.9 during gastrulation.

We originally isolated a novel helix-loop-helix DNA binding domain protein (LOC733709), now suggested as Hes5.9, by screening the possible target genes of the FGF signaling during gastrulation. We characterized the roles of Hes5.9 in embryogenesis, focusing on gastrulation in particular. Compared with humans, Xenopus has the same subfamilies (Hes1-Hes7), but more Hes genes, about 37. These Hes genes are involved in neurogenesis, somitogenesis (Hes1, Hes5, Hes7, etc.) [35], and midbrain-hindbrain boundary formation (Hes7.1) [36]. Hes5 genes are located on the same chromosome, especially Hes5.3-Hes5.10 located in the Hes5.3 gene cluster. Most of these genes are downstream targets of the Notch signaling. As a Hes5 gene member, Hes5.9 contains conserved Notch signaling regulating promoter sequences. Moreover, the mRNA expression levels of Hes5.9 were significantly influenced by either chemical or genetic interference of the Notch signaling (Figure 2). This evidence strongly indicates that Hes5.9 would also be a target of the Notch signaling.

A previous study suggested that all 37 Hes genes, except Hes2, are zygotically expressed in early embryonic stages, and peak from the late gastrula to the late neurula stages (stage 12-20) [37]. Here, we found that Hes5.9 was another maternally expressed Hes gene, which was highly expressed before the mid blastula transformation (MBT), and reached a peak during the neurula stages (Figure 3). Intriguingly, the expression patterns of Hes5.9 are very different from Hes5.7; based on the Transcriptome Database (http://jason.chuang.ca/research/xenopus/refseq.html). Therefore, compared with other Hes genes, even Hes5.7, Hes5.9 performs relatively unique roles during embryogenesis, especially during gastrulation.

The temporal expression pattern of Hes5.9 mRNA revealed that Hes5.9 was a maternally expressed gene, which was expressed throughout embryonic development and reached a plateau during the gastrula stage and the neurula stage. We also examined its spatial distribution by WISH, which suggested that Hes5.9 asymmetrically localized along with the animal-vegetal axis, and was mainly detected at the animal pole. During gastrulation, Hes5.9 is expressed predominantly throughout the mesoderm. As development proceeds, Hes5.9 is detected in the neural tube, somites, tailbud, brain, neural crest, otic vesicle, and eyes (Figure 3 and Figure S2). The FGF signaling has been implicated during several phases of early embryogenesis [7], which contributes to the establishment of distinct types of mesoderm [38]. Meanwhile, the Notch signaling is involved early in the induction of the three germ layers [2], and later, playing important roles in somitogenesis and neural system development [39]. We further investigated the association of Hes5.9 and the FGF signaling pathway during embryonic development by inhibiting FGFR via SU5402 [40] or overexpression of Fgf $8 b \mathrm{mRNA}$ [41]. Here, we found evidence that the FGF signaling pathway is essential for the transcription of Hes5.9 during gastrulation and neurulation (Figures 4 and 5).

It has been reported that the FGF signaling pathway regulated both mesoderm migration and convergent extension movements [42-44]. The embryos treated with the SU5402 at the gastrula stage significantly decreased the expression level of Hes5.9, which was accompanied by delayed gastrulation and ultimately open blastopore (Figures 4 and 5). Therefore, our results indicate that Hes5.9 is regulated both by FGF and Notch signaling during gastrulation, and maybe an important gene for coordinating the FGF and Notch signaling during the gastrula and even the neurula stages. Although treatment with SU5402 caused abnormal embryonic development, we cannot exclude the possibility that the observed phenotype may be caused by the concomitant ectopic expression of Hes5.9. To investigate the character of Hes5.9 during embryogenesis, we specifically knocked down Hes5.9 by microinjecting with the morpholino antisense nucleotides that were selectively designed to block Hes5.9 translation and splicing, respectively (Supplementary Figure S3). It showed that both gastrulation and neurulation were impaired. The embryos injected with Hes5.9-MO exhibit delayed mesoderm involution and failed 
to close the blastopore, which ultimately results in blastopore and neural tube open, and shorter axis embryos at later development (Figure 6). Similar phenotypes were obtained from ectopic expression of Hes5.9 (Figure 7) that both mesoderm convergent extension and mesoderm migration were impaired by dorsally microinjecting Hes5.9 mRNA (Figure 8). Meanwhile, we also found that downregulated genes were significantly enriched in adherence, and cytoskeletal remolding (Figure 9C and Figure S3). Consistently, Hes genes could also be required to control genes involved in cytoskeletal remodeling and the cell shape change, which are needed for initiating the migration itself $[45,46]$. That is also represented by the expression changes of genes, which are involved in the migration process, such as some extracellular matrix molecules and their receptors, cell adhesion molecules, and guide molecules. And the expression levels of those markers were also regulated by Hes5.9, either in whole embryos or explant tissues, further suggesting that Hes5.9 plays important roles in cell fate specification. In general, these results suggest a crucial role of Hes5.9 on gastrulation, that is Hes5.9 may coordinate the FGF and Notch signaling to fine-tune the cell fate specification and morphogenetic movements [2].

Unexpectedly, we also found that the expression level of Xnr3, a target of the maternal Wnt/ $\beta$-catenin pathway, was significant upregulated after overexpression of Hes5.9 (Figure 7H). It seems contradictory to the previous report that Xnr3 was supposed to be inhibited by the Notch signaling [47]. However, Xnr3 is also reported to require the FGF signaling to induce cell elongation movements and thus allocating cells from the organizer [48]. Thus, it is possible that Xnr3 and Hes5.9 coordinate gastrulation in different regions of the mesoderm, which, however, needs further investigation.

In conclusion, we characterized a novel Hes gene (Hes5.9) in Xenopus tropicalis. Our data suggest that Hes5.9 plays important roles in gastrulation and neurulation, through regulating cell fate determination and convergent extension. Further exploration of the possible roles of Hes5.9 in the coordination of the FGF and Notch pathways will bring new insights into the regulation of embryogenesis and organogenesis in future investigations.

Supplementary Materials: The following are available online at http://www.mdpi.com/2073-4425/11/11/1363/s1, Figure S1: Genomic structure of the Xenopus tropicalis Hes5.9 gene, Figure S2: The WISH of gastrulation embryos and transversal section, Figure S3: Three kinds of Hes5.9-MOs efficiently knockdown Hes5.9, Table S1: Ex.1 OvervsCtrl_all.DEG_KEGG_pa, Table S2: gene.description.

Author Contributions: X.H. and P.C. designed the experiments. X.H., Y.Z., S.Y. and P.C. conducted the experiments; M.W. and Y.Z. analyzed the data. S.Y. and L.Z. wrote the manuscript. X.H. and P.C. reviewed and edited the manuscript. All authors have read and agreed to the published version of the manuscript.

Funding: This study was supported by the National Natural Science Foundation of China $(31301148,31271560$ and 30871419).

Acknowledgments: We thank Weiyang Shi and Hao Lin for their constructive suggestions to this study.

Conflicts of Interest: The authors declare no conflict of interest.

\section{References}

1. Kiecker, C.; Bates, T.; Bell, E. Molecular specification of germ layers in vertebrate embryos. Cell. Mol. Life Sci. 2015, 73, 923-947. [CrossRef] [PubMed]

2. Revinski, D.R.; Paganelli, A.R.; Carrasco, A.E.; López, S.L. Delta-Notch signaling is involved in the segregation of the three germ layers in Xenopus laevis. Dev. Biol. 2010, 339, 477-492. [CrossRef] [PubMed]

3. Solnica-Krezel, L.; Sepich, D.S. Gastrulation: Making and Shaping Germ Layers. Annu. Rev. Cell Dev. Biol. 2012, 28, 687-717. [CrossRef] [PubMed]

4. Takeuchi, M.; Nakabayashi, J.; Sakaguchi, T.; Yamamoto, T.S.; Takahashi, H.; Takeda, H.; Ueno, N. The prickle-Related Gene in Vertebrates Is Essential for Gastrulation Cell Movements. Curr. Biol. 2003, 13, 674-679. [CrossRef] [PubMed]

5. Goto, T.; Davidson, L.; Asashima, M.; Keller, R. Planar Cell Polarity Genes Regulate Polarized Extracellular Matrix Deposition during Frog Gastrulation. Curr. Biol. 2005, 15, 787-793. [CrossRef] [PubMed]

6. Tada, M.; Heisenberg, C.-P. Convergent extension: Using collective cell migration and cell intercalation to shape embryos. Development 2012, 139, 3897-3904. [CrossRef] [PubMed] 
7. Dorey, K.; Amaya, E. FGF signalling: Diverse roles during early vertebrate embryogenesis. Development 2010, 137, 3731-3742. [CrossRef]

8. Böttcher, R.T.; Niehrs, C. Fibroblast Growth Factor Signaling during Early Vertebrate Development. Endocr. Rev. 2004, 26, 63-77. [CrossRef]

9. Itoh, N. The Fgf Families in Humans, Mice, and Zebrafish: Their Evolutional Processes and Roles in Development, Metabolism, and Disease. Biol. Pharm. Bull. 2007, 30, 1819-1825. [CrossRef]

10. Sivak, J.M.; Petersen, L.F.; Amaya, E. FGF Signal Interpretation Is Directed by Sprouty and Spred Proteins during Mesoderm Formation. Dev. Cell 2005, 8, 689-701. [CrossRef]

11. Shi, S.; Stanley, P. Evolutionary Origins of Notch Signaling in Early Development. Cell Cycle 2006, 5, 274-278. [CrossRef] [PubMed]

12. Hori, K.; Sen, A.; Artavanis-Tsakonas, S. Notch signaling at a glance. J. Cell Sci. 2013, 126, $2135-2140$. [CrossRef] [PubMed]

13. Ohtsuka, T.; Sakamoto, M.; Guillemot, F.; Kageyama, R. Roles of the Basic Helix-Loop-Helix GenesHes1andHes5in Expansion of Neural Stem Cells of the Developing Brain. J. Biol. Chem. 2001, 276, 30467-30474. [CrossRef] [PubMed]

14. Hong, C.-S.; Saint-Jeannet, J.-P. The b-HLH transcription factor Hes3 participates in neural plate border formation by interfering with Wnt/ $\beta$-catenin signaling. Dev. Biol. 2018, 442, 162-172. [CrossRef] [PubMed]

15. Glavic, A.; Silva, F.; Aybar, M.J.; Bastidas, F.; Mayor, R. Interplay between Notch signaling and the homeoprotein Xiro1 is required for neural crest induction in Xenopus embryos. Development (Camb. Engl.) 2003, 131, 347-359. [CrossRef]

16. Coffman, C.; Harris, W.; Kintner, C. Xotch, the Xenopus homolog of Drosophila notch. Science 1990, 249, 1438-1441. [CrossRef]

17. Ito, M.; Katada, T.; Miyatani, S.; Kinoshita, T. XSu(H)2 is an essential factor for gene expression and morphogenesis of the Xenopus gastrula embryo. Int. J. Dev. Biol. 2007, 51, 27-36. [CrossRef]

18. Ma, Q.; Kintner, C.; Anderson, D.J. Identification of neurogenin, a Vertebrate Neuronal Determination Gene. Cell 1996, 87, 43-52. [CrossRef]

19. López, S.L.; Paganelli, A.R.; Siri, M.V.R.; Ocaña, O.H.; Franco, P.; Carrasco, A.E. Notch activates sonic hedgehog and both are involved in the specification of dorsal midline cell-fates in Xenopus. Development 2003, 130, 2225-2238. [CrossRef]

20. Shook, D.R.; Keller, R. Mechanisms, mechanics and function of epithelial-mesenchymal transitions in early development. Mech. Dev. 2003, 120, 1351-1383. [CrossRef]

21. Favarolo, M.B.; López, S.L. Notch signaling in the division of germ layers in bilaterian embryos. Mech. Dev. 2018, 154, 122-144. [CrossRef] [PubMed]

22. Modrell, M.S.; Tidswell, O.R.; Baker, C.V.H. Notch and Fgf signaling during electrosensory versus mechanosensory lateral line organ development in a non-teleost ray-finned fish. Dev. Biol. 2017, 431, 48-58. [CrossRef] [PubMed]

23. Lloyd-Lewis, B.; Mourikis, P.; Fre, S. Notch signalling: Sensor and instructor of the microenvironment to coordinate cell fate and organ morphogenesis. Curr. Opin. Cell Biol. 2019, 61, 16-23. [CrossRef] [PubMed]

24. Kawamura, A.; Koshida, S.; Hijikata, H.; Sakaguchi, T.; Kondoh, H.; Takada, S. Zebrafish Hairy/Enhancer of split protein links FGF signaling to cyclic gene expression in the periodic segmentation of somites. Genes Dev. 2005, 19, 1156-1161. [CrossRef]

25. Doetzlhofer, A.; Basch, M.L.; Ohyama, T.; Gessler, M.; Groves, A.K.; Segil, N. Hey2 Regulation by FGF Provides a Notch-Independent Mechanism for Maintaining Pillar Cell Fate in the Organ of Corti. Dev. Cell 2009, 16, 58-69. [CrossRef] [PubMed]

26. Voelkel, J.E.; Harvey, J.A.; Adams, J.S.; Lassiter, R.N.; Stark, M.R. FGF and Notch signaling in sensory neuron formation: A multifactorial approach to understanding signaling pathway hierarchy. Mech. Dev. 2014, 134, 55-66. [CrossRef]

27. Davis, R.L.; Turner, D.L.; Evans, L.M.; Kirschner, M.W. Molecular Targets of Vertebrate Segmentation: Two mechanisms control segmental expression of xenopus hairy2 during somite formation. Dev. Cell 2001, 1, 553-565. [CrossRef]

28. Lamar, E.; Kintner, C. The Notch targets Esr1 and Esr10 are differentially regulated in Xenopus neural precursors. Development 2005, 132, 3619-3630. [CrossRef] 
29. Davis, R.L.; Turner, D.L. Vertebrate hairy and Enhancer of split related proteins: Transcriptional repressors regulating cellular differentiation and embryonic patterning. Oncogene 2001, 20, 8342-8357. [CrossRef]

30. Hopwood, N.; Pluck, A.; Gurdon, J. Myod expression in the forming somites is an early response to mesoderm induction in xenopus embryos. EMBO J. 1989, 8, 3409. [CrossRef]

31. Groves, J.A.; Hammond, C.L.; Hughes, S.M. Fgf8 drives myogenic progression of a novel lateral fast muscle fibre population in zebrafish. Development. 2005, 132, 4211-4222. [CrossRef] [PubMed]

32. Stylianou, P.; Skourides, P.A. Imaging morphogenesis, in Xenopus with Quantum Dot nanocrystals. Mech. Dev. 2009, 126, 828-841. [CrossRef] [PubMed]

33. Wallingford, J.B.; Fraser, S.E.; Harland, R.M. Convergent extension: The molecular control of polarized cell movement during embryonic development. Dev. Cell 2002, 2, 695-706. [CrossRef]

34. Wallingford, J.B. Planar Cell Polarity and the Developmental Control of Cell Behavior in Vertebrate Embryos. Annu. Rev. Cell Dev. Biol. 2012, 28, 627-653. [CrossRef] [PubMed]

35. Harima, Y.; Imayoshi, I.; Shimojo, H.; Kobayashi, T.; Kageyama, R. The roles and mechanism of ultradian oscillatory expression of the mouse hes genes. Semin. Cell Dev. Biol. 2014, 34, 85-90. [CrossRef]

36. Takada, H.; Hattori, D.; Kitayama, A.; Ueno, N.; Taira, M. Identification of target genes for the Xenopus Hes-related protein XHR1, a prepattern factor specifying the midbrain-hindbrain boundary. Dev. Biol. 2005, 283, 253-267. [CrossRef]

37. Watanabe, M.; Yasuoka, Y.; Mawaribuchi, S.; Kuretani, A.; Ito, M.; Kondo, M.; Ochi, H.; Ogino, H.; Fukui, A.; Taira, M.; et al. Conservatism and variability of gene expression profiles among homeologous transcription factors in Xenopus laevis. Dev. Biol. 2017, 426, 301-324. [CrossRef]

38. Fletcher, R.B.; Harland, R.M. The role of FGF signaling in the establishment and maintenance of mesodermal gene expression inXenopus. Dev. Dyn. 2008, 237, 1243-1254. [CrossRef]

39. Wahi, K.; Bochter, M.S.; Cole, S.E. The many roles of Notch signaling during vertebrate somitogenesis. Semin. Cell Dev. Biol. 2016, 49, 68-75. [CrossRef]

40. Chung, H.A.; Hyodo-Miura, J.; Kitayama, A.; Terasaka, C.; Nagamune, T.; Ueno, N. Screening of FGF target genes in Xenopusby microarray: Temporal dissection of the signalling pathway using a chemical inhibitor. Genes Cells Devoted Mol. Cell. Mech. 2004, 9, 749-761. [CrossRef]

41. Dubrulle, J.; Pourquié, O. Fgf8 mRNA decay establishes a gradient that couples axial elongation to patterning in the vertebrate embryo. Nature 2004, 427, 419-422. [CrossRef] [PubMed]

42. Shi, W.; Peyrot, S.M.; Munro, E.; Levine, M. FGF3 in the floor plate directs notochord convergent extension in the Ciona tadpole. Development 2008, 136, 23-28. [CrossRef] [PubMed]

43. Chung, H.A.; Hyodo-Miura, J.; Nagamune, T.; Ueno, N. FGF signal regulates gastrulation cell movements and morphology through its target NRH. Dev. Biol. 2005, 282, 95-110. [CrossRef] [PubMed]

44. Bae, Y.-K.; Trisnadi, N.; Kadam, S.; Stathopoulos, A. The role of FGF signaling in guiding coordinate movement of cell groups: Guidance cue and cell adhesion regulator? Cell Adhes. Migr. 2012, 6, 397-403. [CrossRef] [PubMed]

45. Perris, R.; Perissinotto, D. Role of the extracellular matrix during neural crest cell migration. Mech. Dev. 2000, 95, 3-21. [CrossRef]

46. Vega-Lopez, G.; Bonano, M.; Tríbulo, C.; Fernández, J.P.; Agüero, T.H.; Aybar, M.J. Functional analysis ofHairygenes inXenopusneural crest initial specification and cell migration. Dev. Dyn. 2015, 244, 988-1013. [CrossRef]

47. Colabianchi, A.M.C.; Revinski, D.R.; Encinas, P.; Baez, M.V.; Monti, R.J.; Abinal, M.R.; Kodjabachian, L.; Franchini, L.F.; López, S.L. Notch1 is asymmetrically distributed from the beginning of embryogenesis and controls the ventral center. Development 2018, 145, dev159368. [CrossRef]

48. Yokota, C.; Kofron, M.; Zuck, M.; Houston, D.W.; Isaacs, H.; Asashima, M.; Wylie, C.; Heasman, J. A novel role for a nodal-related protein; Xnr3 regulates convergent extension movements via the FGF receptor. Development 2003, 130, 2199-2212. [CrossRef]

Publisher's Note: MDPI stays neutral with regard to jurisdictional claims in published maps and institutional affiliations. 